\title{
V-CHAIN: MIGRATING FROM EXTENDED TO VIRTUAL ENTERPRISE WITHIN AN AUTOMOTIVE SUPPLY CHAIN
}

\author{
Ángel Ortiz Bas ${ }^{(1)}$ \\ Rubén Darío Franco ${ }^{(2)}$ \\ Marc Alba ${ }^{(3)}$ \\ (1) aortiz@cigip.upv.es, ${ }^{(2)} d$ franco@cigip.upv.es \\ CIGIP Research Centre \\ Universidad Politécnica de Valencia \\ Camino de Vera S/N. CP 46022. Valencia \\ (3) marc_alba@dmr.ca \\ DMR Consulting SPAIN
}

\begin{abstract}
V-CHAIN objective is to migrate from an Extended Enterprise to a Virtual Enterprise organizational model. Its aim is to improve the overall Scheduling and Sequencing Business Process performance by means of a virtual operator deployment that takes charge of process monitoring and execution.

The process has been redesigned from three main interrelated dimensions: the Business Process Management, Knowledge Management and the Technological Framework.
\end{abstract}

\section{INTRODUCTION}

The Virtual Enterprise for the Supply Chain Management (SCM) project, V-CHAIN aims to develop a Virtual Enterprise framework for SCM context in order to improve the overall performance of the Scheduling and Sequencing Business Process performance for all involved partners. The project scope includes Original Equipment Manufacturer (OEM), the logistic operator and first tier suppliers of an automotive supply chain.

As general objectives, the project will:

- Reduce the demand and sequencing variation of the scheduling PP in the short and mid-term.

- Optimise material, decision \& information flows management.

- Make a collaborative planning \& scheduling process

- Develop an Information and Communication framework supporting such goals.

This work presents results gained during Pilot 1 when the technological framework needed to support the virtual enterprise life's cycle was developed, how it is related to the migration path, and major tools already implemented.

The paper is structured as follow: Section 2 introduces the problem under study; Section 3 describes the overall migration path methodology of V-CHAIN; Section 4, 
describes de Technological Framework; Section 5 introduces the virtual Operator for Planning and Sequencing. Finally, some conclusions are stated.

\section{VIRTUAL ENTERPRISE MOTIVATIONS}

Early project stages were focused on getting extensive knowledge regarding Supply Chain (SC) current status and determine a technological project starting point. The main objective was to identify potential improvement areas.

Most interviewed partners identified the lack and inconsistency of information, functional and decisional flows as their major concerns; in second place, a collaborative infrastructure appeared as a desirable mechanism where incidences and suppliers constraints were included later during production planning process.

In the automotive company under study, the Production Planning business process tries to optimise Production Plans by looking for regular consumptions of raw materials and car components in order to minimise cost, reduce inefficiencies and to avoid missing parts. In many cases, there exist innumerable variability sources that make plans extremely difficult to be carried out "as is". External forces such as supply delays or failed components cause a "missing part" and the associated order cannot be manufactured entirely until the problem is solved. In other cases, unexpected OEM's internal causes change the predicted sequence. The challenge to the SC is to quickly react to those unforeseen events in order to avoid unfulfilled orders.

Reengineering of supply chain business process requires the extended partner's collaboration to face those situations. This "collaboration" must be understood as a structured and systematic way of reaching mutually agreed decisions moving towards a win-win partnership.

Virtual Enterprises tends to be more democratic organisational models (Camarinha-Matos and Afsarmanesh, 1999), where partners increase their visibility within the network and a complementary decisional flow emerges to represent a balancing power that act as such a win-win relationship enabler. In this sense, Martinez (Martinez et al. 2001), says that the main objective of a virtual enterprise is to allow a number of organisations to rapidly develop a common working environment; hence managing a collection of resources provided by the participating organisations toward the attainment of some common goals. This kind of model applied to a SC context implies some changes in the OEM's role where they must be able to open their information systems, sharing online production lines status, for instance, and allowing partners to express their capacity and constraints also.

In this scenario the proposed approach has been to set-up a Virtual Enterprise able to manage all aspects, thus allowing every partner involved in the Production Planning, Scheduling and Sequencing Business Process (PPSSBP) to perform it, in a collaborative and win-win scenario. This entity will require an ad hoc ICT platform in order to support distributed business process execution and monitoring.

\section{V-CHAIN MIGRATION PATH}

In order to get a fully operative Virtual Enterprise with proper ICT platform support, migrating from some initial status, the Extended Enterprise model (AS-IS State), suitable infrastructures are needed. 
This VE deployment requires the building of new functionalities, in terms of information systems that supports the new meta-management level to be introduced, but much effort is also spent into legacy systems integration (TO-BE State). Then, there are two main dimensions where the evolution must be conducted in an integrated way: the Business dimension (includes the organisational, functional and decisional view) that will be reengineered, and the ICT dimension that encompasses all changes to be undertaken regarding the technological platform supporting it.

Based on the previous considerations, the migration path to move from an $\mathrm{EE}$ to a VE identifies six Stages (see Figure 1):

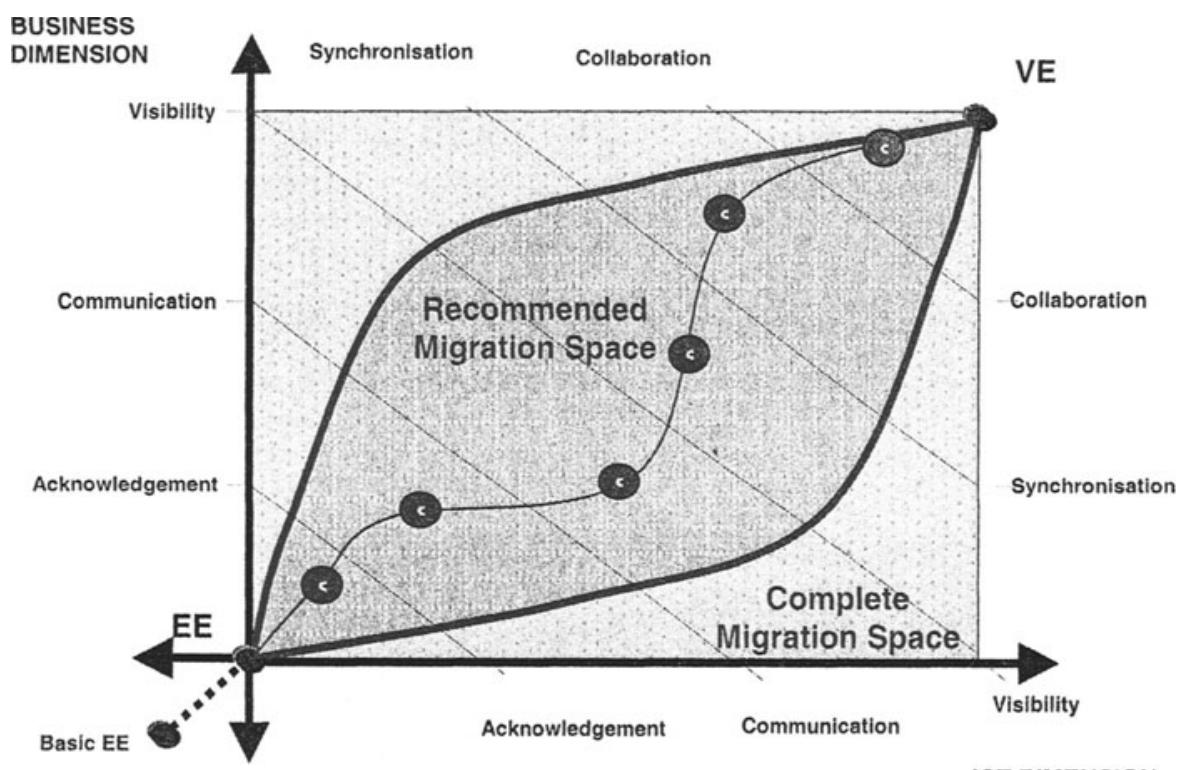

ICT DIMENSION

Figure 1 - The migration path from an EE to a VE

The following table summarises the character of each of the major stages:

Table 1: V-CHAIN Migration Stages

\begin{tabular}{|c|l|}
\hline $\begin{array}{c}\text { Migration } \\
\text { Stage }\end{array}$ & \multicolumn{1}{|c|}{ Description } \\
\hline S1 & $\begin{array}{l}\text { The extended enterprise } \\
\text { This stage represents the initial step in the evolution, which } \\
\text { matches the characteristics introduced for the EE concept } \\
\text { (Browne and Zhang, 1999). }\end{array}$ \\
\hline S2 & $\begin{array}{l}\text { The acknowledged virtual enterprise } \\
\text { The predominant company recognises that companies } \\
\text { involved in the EE must evolve together in order to improve } \\
\text { their collaboration and that the VE model provides an } \\
\text { improvement path. VE paradigm starts to gain adepts at the } \\
\text { strategic level, inside each involved company; an incipient } \\
\text { culture appears, implying the start of a knowledge and }\end{array}$ \\
\hline
\end{tabular}




\begin{tabular}{|c|l|}
\hline S3 & discovery process. The VE is acknowledged and thereby born. \\
\hline S4 & $\begin{array}{l}\text { The communicating virtual enterprise } \\
\text { The first step toward the VE is the achievement of the } \\
\text { communication integration level within the networked } \\
\text { organisation so that it fulfils the principles of both the } \\
\text { communication SC integration level and the VE philosophy. }\end{array}$ \\
\hline $\begin{array}{l}\text { The visible virtual enterprise } \\
\text { Based on the capacity to communicate, the second step toward } \\
\text { the VE is the achievement of the visibility integration level } \\
\text { within the networked organisation so that it fulfils the } \\
\text { principles of both the visibility SC integration level and the } \\
\text { VE philosophy. The issues here are still highly technical and } \\
\text { technological, but business starts to gain importance }\end{array}$ \\
\hline S5 & $\begin{array}{l}\text { The synchronised virtual enterprise } \\
\text { Third step toward the VE is the achievement of the } \\
\text { synchronisation integration level within the networked } \\
\text { organisation. The issues here are more business-oriented. }\end{array}$ \\
\hline S6 & $\begin{array}{l}\text { The collaborative virtual enterprise } \\
\text { The final stage in this path implies the full VE } \\
\text { accomplishment and integration, and its independence as a } \\
\text { single business entity is established. }\end{array}$ \\
\hline
\end{tabular}

In the next sections, a description of the technological framework that allows moving from S1 state to S6 state is developed.

\section{V-CHAIN FRAMEWORK}

Next we will introduce the V-CHAIN Framework under which major process improvements have been developed.

When defining the infrastructure for the supply chain interoperability, two main areas to be covered were identified: Enterprise Application Integration (for internal processes) and Business to Business Integration (for inter-organisational processes).

Both topics were covered by deploying an integration platform provided by a project partner (Vitria) and complementary software components that were then integrated to solve specific problems e.g. algorithms for sequencing planning, or simulation scenarios.

Additional layers were designed in order to fully cover the project scope: the security layer (tackling security policies), real-time data analysis (to monitor supply chain execution) and multi-channel access (allowing users to get updated information about operations). In figure 2 the major components are depicted.

The framework covers the more technological migration stages identified as S2, $\mathrm{S} 3$ and S4 stages, while remaining stages ( $\mathrm{S} 1, \mathrm{~S} 5$ and $\mathrm{S} 6$ ) can be conceived as more business development oriented.

The Operator for Planning and Sequencing, the main V-CHAIN development, has been developed according to this generic framework. 


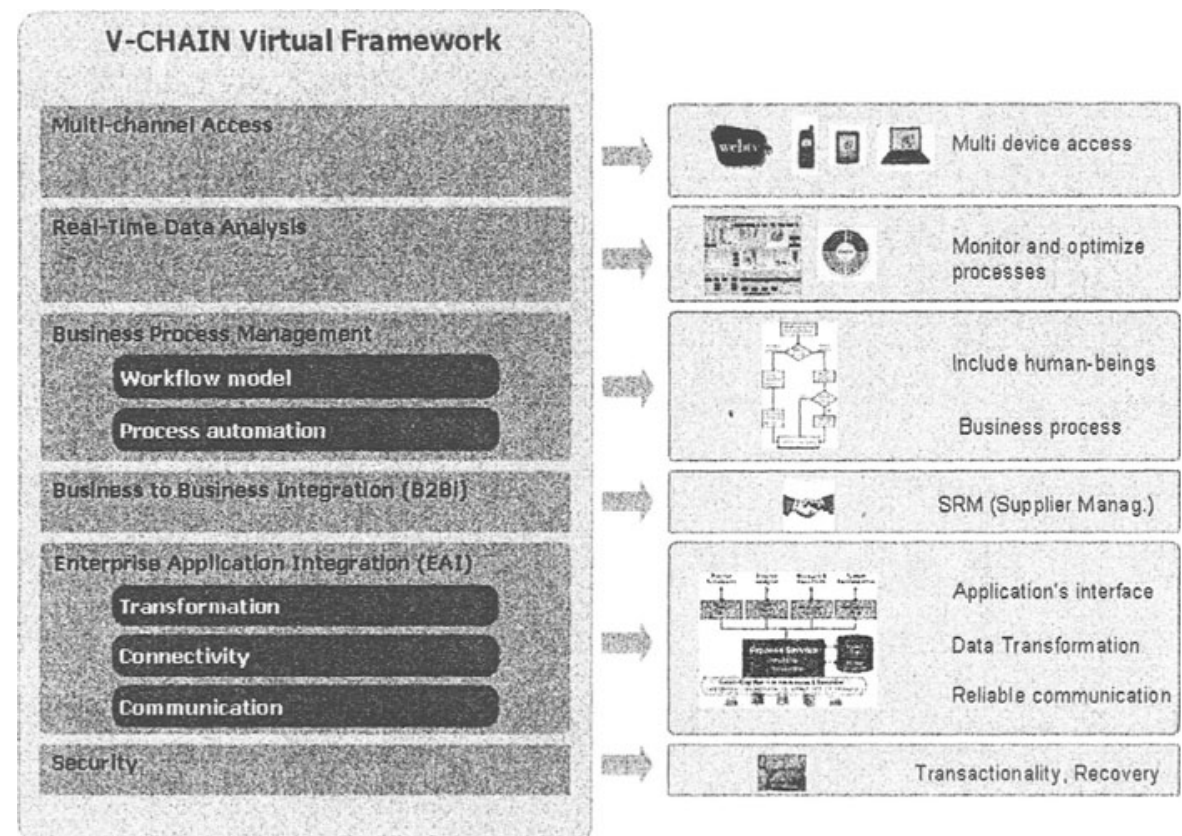

Figure 2 - V-CHAIN Framework

\section{OPERATOR FOR PLANNING AND SEQUENCING (OPS)}

\subsection{OPS objective}

The OPS will be responsible for coordinating and the real-time monitoring of activities related to PPSSBP and establishing well-defined policies and rules that will govern VE life cycle within V-CHAIN. From this point of view, the OPS will enable new flows to be created, whilst at the same time, allowing others to be opened to new players. Thus, those flows related to information access that in the AS-IS state were only available to a few "qualified" suppliers, will now be accessible to any VE participant.

On the other hand, new flows emerge not only at information level but at the decisional level also. One of the most important features that has been included within the OPS is the capability for collecting all suppliers constraints and capacities and including them when the "next vehicle to be assembled" decision must be adopted. In this case, the main goal is to enable suppliers to be able to introduce their own production line status's characterisation, such that the assembler's decisions regarding the modification of production plans can be minimised, so that when they happen, the overall impact can be reduced.

\subsection{OPS Conceptual Architecture}

In order to support the new and improved functionalities explained above, corresponding information systems must be integrated and, when is needed, some 
new developments had to be conducted. The OPS architecture (see Figure 3) can be decomposed in two main blocks: the Business Layer, which encompasses vertical modules of functionality that tackle specific issues and the IT layer which is devoted to achieve the desired level of internal integration and external interoperability for each involved partner applying most concepts of the V-CHAIN framework.

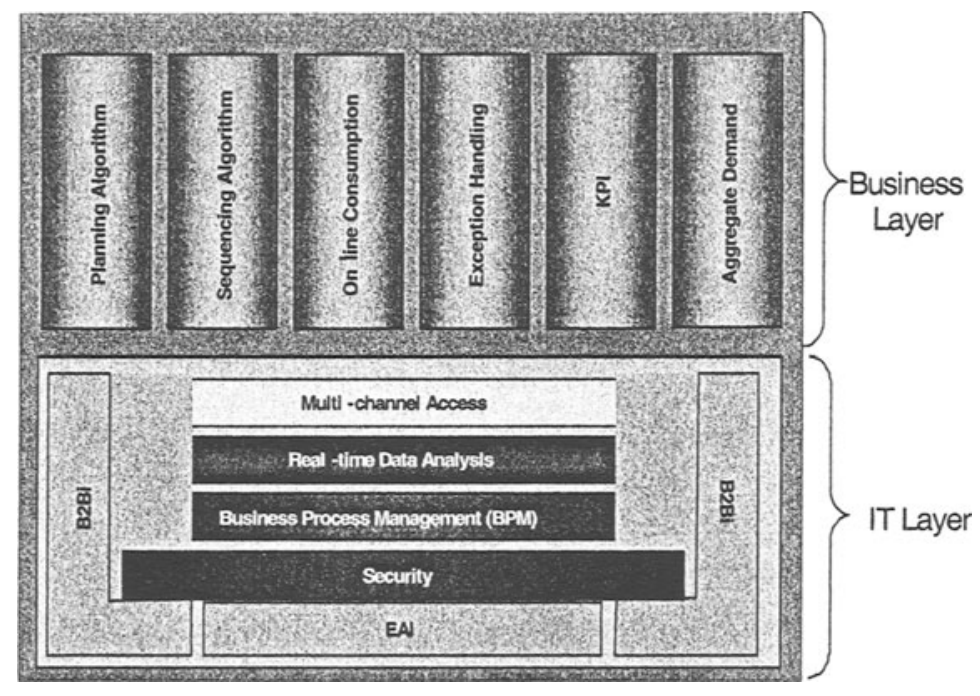

Figure 3 - OPS Architecture

EAI tools were used to connect the OPS with legacy systems. By using Vitria's connectors, information stored in database systems can be provided to the OPS by using some of the XML's schemas designed with such purpose.

Once the information has been gathered, it can be published, after some processing tasks, by using the web portal or it can be forwarded by using multichannel platform capabilities. The B2Bi capabilities allow interconnecting interorganisational business processes by interchanging XML-based documents. Other components are related to secure data access, real-time data monitoring, etc.

Such capabilities can be considered as all-purpose components, or horizontal tools, over which specific, ad-hoc, problem solving components can be "plugged" to exploit such integration features or channel access.

The business layer corresponds to specific components that had been designed to solve some particular functionality related to the process under consideration. Thus, there are specific components that manage: a) Partner's constraints; b) Incidences in the supply chain; c) Algorithms for sequencing and scheduling; d) Analysis tools; Scenarios simulator; and e) the V-CHAIN Cockpit.

\subsection{OPS Technical implementation}

The technical implementation of OPS functionalities is a result of the Vitria platform deployment and ad-hoc components properly integrated on top of it. Figure 4 introduces the currently deployed architecture: 


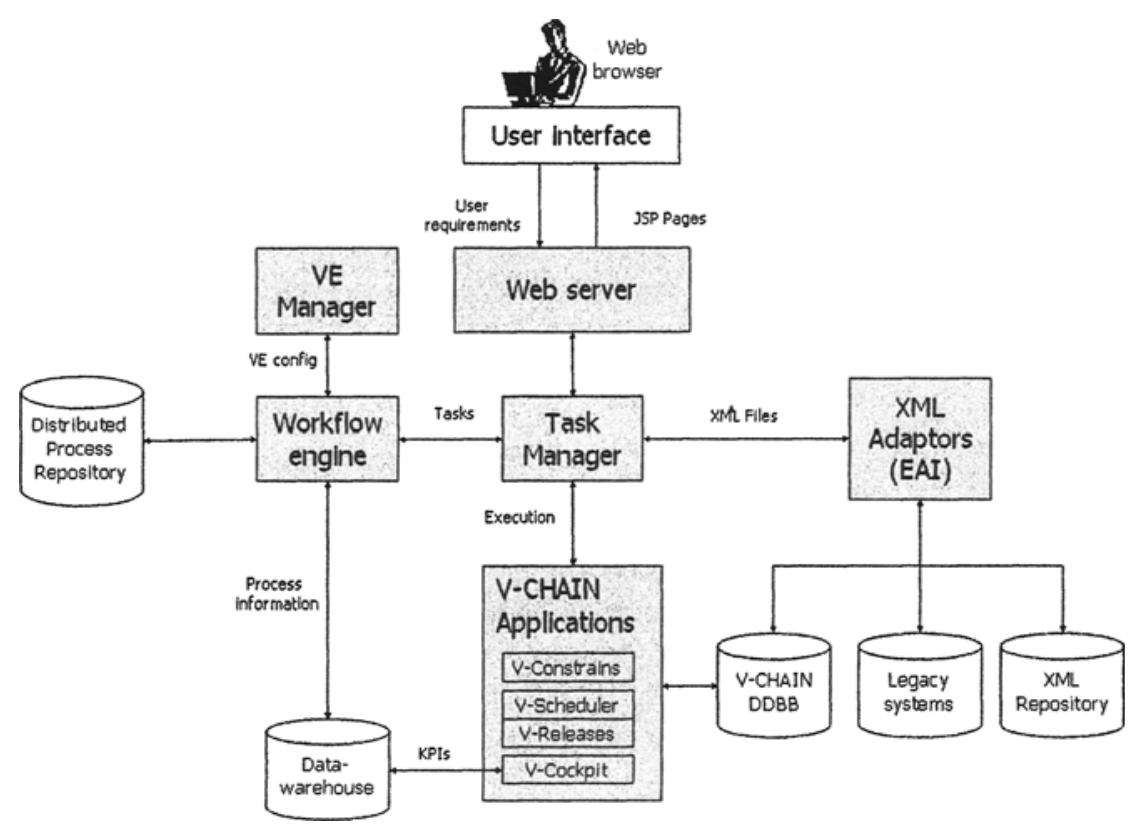

Figure 4 - OPS Technical implementation

The VE Manager allows the definition and setting up of major topics related to the VE. It can be used to create users, security policies, algorithms strategies and most parameters that will configure the OPS behaviour. It also enables the design of distributed business processes, stored in a distributed business process repository, whose instances will be executed later by the workflow engine. It is responsible for tasks execution and monitoring, and, complementary, to provide information to the data warehouse. When a user sends a requirement to the OPS Interface (expected multi-channel), in most cases via a web browser, it is assigned to the Task Manager that will be responsible for performing such tasks. This requires the invocation of some V-CHAIN applications, for instance the V-Scheduler, which access proper information sources by means of the XML adaptors.

These adaptors are responsible for EAI activities, integrating legacy systems data, current V-CHAIN databases and the XML repository in order to provide reliable and accurate information.

Most applications work jointly with the workflow engine and are responsible for providing the information that allows VE monitoring by using the V-CHAIN cockpit. It has been designed to support both qualitative and quantitative Key Performance Indicators.

\subsection{OPS Business Case Implementation}

In the real implementation of the OPS in Ford's Pilot of the V-CHAIN project, there have been several problems along the project's life that we have faced and solved: difficulties to model implicit business processes spread in multiple companies; integration of information from multiple sources and with different end- 
user requirements in order to process and present it; complex access to host systems where most of the information is stored; change philosophy of the systems and the people accessing them, from a pull model where the people have to go into the system every time they want to check if there are problems, to a new push model in which the systems send to the users the information needed to solve those problems.

All these implementation difficulties have been solved and we can say that the overall performance of the platform is very satisfactory not only for the current pilot situation where only few partners can access the system, but in the near future when dozens of new suppliers were plugged into the platform.

These new suppliers will have three options to connect to the system:

- Only Web browser access to the applications. This implies that they can only use applications, download files and manually enter the information needed to perform collaborative business processes like sequencing one.

- Web access plus a small B2Bi component which allows the possibility to automatically upload the information for collaborative processes.

- Usage of a full B2Bi architecture which allows, besides the above functionalities, to directly connect this supplier's systems with the systems of the OPS, the manufacturer or other suppliers.

\section{CONCLUSIONS}

This work presents a technological framework implemented to set-up a Virtual Enterprise that solves a real scenario in an automotive supply chain.

Although this is a long-term relationship scenario, business process complexity and dynamicity provides an excellent opportunity to deploy virtual enterprises models and architectures. Accordingly, we consider that the proposed solution may be useful since it follows an incremental approach over existing systems, process and policies. Furthermore, it has been implemented addressing adequately some of the requirements defined for the enterprises, namely: return of investment, consideration of current systems, increasing a win-win partnership.

\section{ACKNOWLEDGMENTS}

This work has been developed in the Project V-CHAIN (Virtual Enterprise for Supply Chain Management-GRD1-2000-25881) funded by the European Commission under the "Competitive and Sustainable Growth" Programme.

\section{REFERENCES}

1. Camarinha-Matos, L. and Afsarmanesh, H. Flexible coordination and information sharing for virtual enterprises in PRODNET. APMS 1999: 67-75

2. Martinez, M.T., P. Fouletier, K.H. Park, J. Favrel (2001). Virtual Enterprise - organisation, evolution and control (2001). Int. J. Production Economics 74. 225-238

3. Browne, J and Zhang, J. (1999). Extended and Virtual Enterprises - similarities and differences. International Journal of Agile Management Systems 1/1, pp. 30-36

4. Ortiz, A., Hawa, M. (2002b). V-CHAIN (Virtual Enterprise for Supply Chain Management) European Project. Deliverable 2.2. Virtual Enterprise Report 